\title{
THE PLACE OF THE ETYMON AND THE PHONETIC MATRIX IN THE ARABIC MENTAL LEXICON
}

\begin{abstract}
Abdessatar Mahfoudhi
KING SAUD UNIVERSITY, RIYADH*

Two units have traditionally been proposed as the basis of the organization of the Arabic lexicon: the root and the stem. The root approach, the most common, is based on the root and pattern theory of Arabic morphology (e.g., McCarthy 1981), which contends that derivation is based on the interleaving of consonantal roots into patterns. By contrast, the stem approach is based on the stem-based theory of Arabic morphology (e.g., Benmamoun 1999) whose main tenet is that the stem is the basis of derivation. More recently, Bohas (e.g., 2000) has challenged these two approaches. He proposes that the Arabic lexicon is organized in three layers under three units: the phonetic matrix, the etymon, and the 'radical'. These three proposals have different implications for the Arabic mental lexicon. This study discusses these theories with a focus on the validity of the notions of the etymon and matrix in the Arabic mental lexicon in light of old and new psycholinguistic evidence. Keywords: Arabic morphology, root, pattern, etymon, phonetic matrix, psycholinguistics, lexicon
\end{abstract}

\section{Introduction}

Most Arabic dictionaries have been organized around the root. ${ }^{1}$ This assumption is based on the traditional root and pattern theory of morphology. The modern proponents of this theory (Cantineau 1950a, McCarthy 1981) contend that derivation is based on the interleaving of roots into patterns, both of which are abstract unpronounceable units. The root, often made of three discontinuous consonants, carries the core meaning of the word, and the pattern, made of the root consonant slots, vowels, and consonant affixes, has the syntactic meaning. Therefore, the root, being the main carrier of meaning, has been used in most Arabic dictionaries as the head of lexical entries. The other competing theory of morphology, the stembased theory (e.g., Ratcliffe 1997), has different implications for the

* The author is currently associated with the Center for Child Evaluation and Teaching, Kuwait, and the United Nations Development Program in Kuwait.

${ }^{1}$ I would like to thank Georges Bohas and anonymous reviewers from the Journal of Arabic and Islamic Studies for their helpful comments on earlier versions of this paper. Any infelicities of any kind are mine alone. 
Arabic lexicon. The main tenet of the stem-based theory is that the stem is the basis of derivation, as is the case in concatenative languages, and by implication the basis of the organization of the lexicon. Psycholinguistic evidence on the validity of these two proposals has been predominantly in favor of the root and pattern theory. Recently, Bohas $(1997 ; 2000)$ has proposed that the root should be replaced by the biconsonantal etymon, which is the segmental manifestation of the more abstract notion of the phonetic matrix, in the organization of the Arabic lexicon. These three theories ${ }^{2}$ have different consequences for theories of the Arabic mental lexicon, that is, the idealized mental representation of words in the Arabic mind, a topic that may have considerable implications for lexicography. The stem-based theory is in line with the tenets of the full-listing hypothesis of lexical processing (e.g., Butterworth 1983), which assumes that words are represented and accessed as whole units. Both the morpheme-based theory of morphology and Bohas's matrix and etymon theory are congruent with the more common dual access hypothesis of lexical processing (e.g., Caramazza, Laudanna, and Romani 1988), which assumes that most complex words are represented as separate morphemes. Yet, while the root and pattern theory predicts that the root and the pattern are used in mental representation, Bohas's theory of the Arabic (and Semitic) lexicon predicts that the matrix and the etymon, and probably the 'radical', are represented in the Arabic (and Semitic) mental lexicon.

The main objective of this study is to review the theory of the etymon/phonetic matrix and test the cognitive validity of the notions of the etymon and the matrix it proposes in light of old and new psycholinguistic evidence; that is, whether they have any special status in the Arabic mental lexicon. The new psycholinguistic evidence reported on in this study is based on two lexical decision experiments that tested the cognitive validity of the etymon construct in its ordered and non-ordered form and its more abstract form, i.e., the phonetic matrix, in two lexical decision experiments.

The focus will be on the notion of the etymon and its more abstract base, the phonetic matrix, but for the sake of clarity, I provide a brief background about the root and pattern theory as well as the stem/wordbased theory and their relevance for the Arabic mental lexicon. I also summarize the psycholinguistic evidence for these two rival theories: the

2 It is essential to point out that Bohas's theory, as he insists (in a personal communication, 3 June 2007), is not a theory of morphology, but a theory of the Arabic (and Semitic) 'lexique'/lexicon. 
root and pattern theory and the stem-based theory. While the study is on Arabic, where relevant, reference (mostly in footnotes) is made to other Semitic languages that are also relatively well-researched, especially Hebrew.

The remainder of this paper is organized as follows. The first section discusses the classical constructs of the root and stem proposed in their respective theories of Arabic morphology and their implications for the Arabic mental lexicon. The second section discusses the notion of the etymon and phonetic matrix in Bohas's theory of the Arabic lexicon. The third section reviews previous psycholinguistic studies that have dealt with and have been cited as evidence for the cognitive validity of the root, the pattern, and the etymon. Evidence for the stem is almost nonexistent. The fourth section is a report on two new experiments that used a lexical decision task to examine the cognitive validity of the etymon and the phonetic matrix in their ordered and non-ordered forms. Finally, the results of the two experiments are discussed in light of previous results, and their implications are drawn for theories of Arabic morphology and mental lexicon.

1. Theories of Arabic morphology and their implications for the Arabic mental lexicon

As mentioned above, two main theories, the stem-based theory and the morpheme-based theory, have been proposed to account for the morphology of Arabic (and Semitic in general).

\subsection{The stem-based theory}

The stem-based theory claims that the process of word formation is based on the stem, as is the case in English for instance. Unlike in the morpheme-based theory, the root, mostly a three-consonant discontinuous unit, is considered a part of a paradigmatic relation between words in the stem-based theory (e.g., Ratcliffe 1997, Benmamoun 1999)3. The main argument in support of the word-based analysis is that certain features (e.g., long vowels) in a word are carried over to the derived word. Another argument is that there are many words that cannot be traced to any known root. The stem-based theory has implications for lexical representation/the mental lexicon. The stem-based theory is in line with the tenets of the full-listing hypothesis of lexical processing (e.g., Butterworth 1983), which assumes that words are represented and accessed as

3 See Bat-El (1994) and Ussishkin (1999) for similar arguments for Hebrew morphology and Hoberman and Aronoff (2003) for the verbal morphology of Maltese. 
whole units and not morphemes.

\subsection{The root and pattern theory}

The root-based theory has gone through changes from its early conception, which goes back to the old Arab grammarians (e.g., Ibn Jinnī; see, for instance, Bohas and Guillaume 1984 for a review ${ }^{4}$ ). The traditional view of the old grammarians is clearly laid out in the work of modern structuralists (e.g., Cantineau 1950a; 1950b) and is still common among Arabic scholars (e.g., Rajhi 1974). It postulates that the derivation is based on the mapping of the root (hurüf 'așliyya 'original sounds'), mainly three (and less frequently two or four) discontinuous consonants, onto a pattern (wazn 'measure'). For instance, the word dahala 'enter' is made of the root $d-h-l$ and the pattern $\mathrm{CaCaCa}$. The root carries the core meaning of the word 'entering', and the pattern has the syntactic meaning 'perfective, active'.

A more recent, influential conception of the root and pattern theory is McCarthy's CV-morphology (e.g., McCarthy 1979/1982). CVmorphology, later called prosodic morphology in McCarthy and Prince (1990; 1999), used the main tenets of autosegmental phonology (Goldsmith 1976), particularly the representation on separate tiers of different elements of the word, to account for the morphology of Arabic $^{5}$. In this theory, Arabic morphemes making up words are represented on four separate tiers, each attached to a morpheme node ' $\mu$ ', as illustrated in (1) below. One tier hosts the root and a second tier hosts the vocalic melody made of vowels. Affixes are represented on a third tier. On the fourth tier is the CV-skeleton on which the three other tiers converge. The template is composed of vocalic and consonantal slots. The Obligatory Contour Principle prohibits the existence of identical adjacent elements 'in any autosegmental tier' (McCarthy 1981, 383). Thus, in the case of the vowel morpheme in (1) the association is spread from left to right to the second identical vowel, as shown by the dashed lines.

\footnotetext{
${ }^{4}$ Bohas and Guillaume emphasize that unlike the modern structuralist Semitists (e.g., Cantineau 1950a; 1950b), who suggest that all derivations are a mapping of a root to a template, the old Arab grammarians propose word-to-word derivations in many cases. It is, however, possible to propose root to pattern mapping while still proposing that words are derived from others with some additions, deletions of suffixes as well as a change in vowels (cf. Watson 2002).

${ }^{5}$ McCarthy's work was done on Arabic but was applied to many languages with non-concatenative morphology, such as reduplication, e.g., Marantz 1982 (re: Agta) and Broselow and McCarthy 1983 (re: Samoan).
} 
(1) Derivation of the Arabic word dahalat 'she/it entered': Association of morpheme levels to CV-skeleton

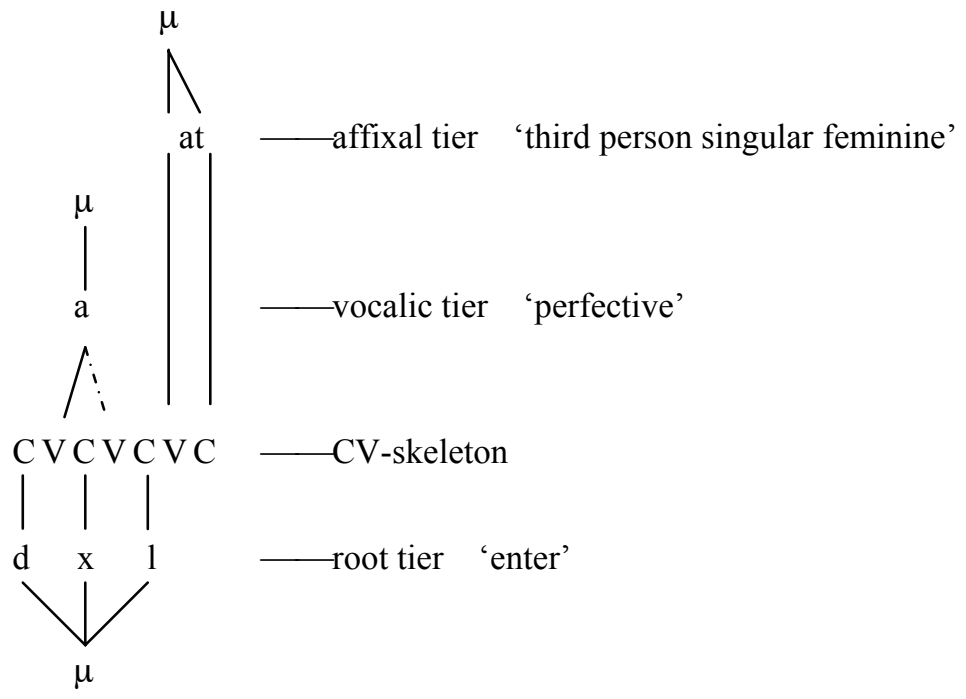

The implications of the traditional root and pattern theory and the CVmorphology theory for the Arabic mental lexicon is that at least the root and the pattern are represented as separate units, in line with both the decompositional hypothesis (e.g., Taft 1981) and the dual-access hypothesis (e.g., Caramazza, Laudanna, and Romani 1988), both of which suggest that (at least some) complex words are accessed and represented as separate morphemes.

2. The etymon and matrix theory of the Arabic lexicon

The etymon and matrix theory has challenged the traditional assumption that the Arabic lexicon is built around mainly tri-consonantal roots. The data in (2) and (3), below, show that an explanation in terms of the root 'ne permet pas de rendre compte des relations phonétiques et sémantiques entre les mots, qu'elle ne permet même pas de les observer' (Bohas 2000, 11). First, the words in (2) (from Bohas 2000, 13) share the same root (in bold) but have very little semantic similarity.

(2) Arabic words with the same root but with different meanings

Word
a. sabara
b. subratun
c. șabiratun
d. muṣtabirun

Gloss

'tie, attach s.th. or s.b. to s.th.'

'a heap of grain'

'a rocky hill, a mountain'

'a heap of meat' 
Second, in (3) (from Bohas 2000, 15), there is a semantic similarity between words that do not share the same root, but only two consonants (in bold).

(3) Arabic words sharing two root consonants

$\begin{array}{lll}\text { a. } & \text { batta } & \text { 'to cut (off)' } \\ \text { b. } & \text { batara } & \text { 'to cut the tail of an animal; to cut (off)' } \\ \text { c. } & \text { inbataca } & \text { 'to be cut off' } \\ \text { d. } & \text { bataka } & \text { 'to cut (off); to separate a part from the whole' } \\ \text { e. } & \text { batala } & \text { 'to cut (off); to separate a part from the whole' } \\ \text { f. } & \text { balata } & \text { 'to cut (off)' } \\ \text { g. } & \text { barata } & \text { 'to cut' } \\ \text { h. } & \text { sabata } & \text { 'to cut (off); to shave one's hair' }\end{array}$

Bohas $(1997 ; 2000)$ calls the two consonants shared by the above words an 'etymon'. He argues that the etymon is a more abstract and fine-grained construct that links semantically-related words that otherwise have different triliteral or quadriliteral roots. It is, therefore, according to him, a better candidate for the organization of the 'lexique' (lexicon) and the semantic relationships between lexical items, and thus should replace the root $(1997,10-14)$. The third consonant of what is traditionally known as the root is considered to be augmented/extended to fill the three-consonantal pattern, a notion also adopted in the etymon theory. The etymon consonants can be non-ordered (e.g., $i^{c}$ talla 'he/it fell sick' and $l a w w a a^{c} a$ 'he/it tormented').

Another reason behind the proposal of the etymon, which should not be mistaken for the traditional bi-consonantal root, as a base of lexical relations and derivation is the existence in the lexicon of Arabic (and other Semitic languages) of a large number of words with only two root consonants. These include, in addition to the many words with a geminated second root consonant, words that have both the first and the second root consonants reduplicated, as in ğarğara 'to drag'. Work done so far on the etymon could identify at least 200 etymons in Arabic (Bohas 2000).

The etymon is the phonemic instantiation of a far more abstract bundle of phonetic features that Bohas calls the phonetic matrix and that he places at the top layer of the structure of the Semitic lexicon, below which are the etymon and then the 'radical' (defined below).

The phonetic matrix (M) is a minimal semantico-phonetic unit that is made of 'une combinaison de traits phonétiques et de noyaux sémiques' (Bohas 2000, 64). It relates via a very complex semantic network words sharing two or more unordered phonetic features (e.g., labial and cor- 
onal) (see appendix A for the phonetic features of the Arabic consonants). Included under the same matrix, then, are words that share either the same etymon (i.e., two phonemes) as in $(4 a-b)$ or only place features in two different phonemes as in $(4 \mathrm{c}-\mathrm{f}$ ) (see appendix B for the list of phonetic matrices in Arabic registered so far in Bohas 1997 and 2000). The shared meaning of the words in (4) having the same phonetic matrix $\{[$ labial], [coronal]\} is the act of hitting without specifying the object of the action (Bohas 2000, 72-73). The etymon is, therefore, a segmental manifestation (in two ordered or non-ordered phonemes) of the more abstract notion of the phonetic matrix. Bohas and Saguer (2005) also argue that the etymon and matrix theory is not only superior to the root theory in capturing the semantic relations between words but also in explaining several issues of polysemy.

(4) Arabic words sharing the phonetic matrix $\{[$ labial], [coronal]\}

$\begin{array}{lll}\text { a. } & \text { habata } & \text { 'to hit' } \\ \text { b. } & \text { habata } & \text { 'to hit' } \\ \text { c. } & \text { habaša } & \text { 'to hit someone and hurt him/her' } \\ \text { d. } & \text { daraba } & \text { 'to hit; to beat up' } \\ \text { e. } & \text { rafaza } & \text { 'to hit; to beat up' } \\ \text { f. } & \text { fat }^{c} a^{\circ} a & \text { 'to hit (on the back)' }\end{array}$

Bohas $(1997 ; 2000)$ proposes that there are five ways by which the etymon develops/is augmented into a 'radical': (i) spreading, (ii) addition, (iii) prefixation, (iv) integration of two etymons, and (v) reduplication.

Bohas $(2000,33)$ thinks that what happens at the level of the 'radical', which is made of an etymon with a prefixed or added consonant and a skeleton with at least one vowel, is morphological. 'Dans les deux premiers niveaux [matrice et étymon], nous nous situions à l'intérieur du lexique, mais ici [au niveau du radical] nous arrivons au moment où intervient la morphologie. La morphologie est organisée sur des schèmes triconsonantiques et le problème posé à ce niveau est donc d'apparier des étymons biconsonantiques avec des schèmes triconsonantiques. C'est à ce niveau que l'étymon biconsonantique est développé pour cadrer avec le schème.' Yet, Bohas's proposal does not say anything about the morphology and whether the etymon is a morphological unit.

3. Psycholinguistic evidence for stems, roots, patterns, and etymons: Previous studies

Having discussed the construct of the etymon and its correlate, the phonetic matrix and the other proposed units, we will now review the major 
research findings on the cognitive relevance of these units.

\subsection{Evidence for the cognitive relevance of roots 6}

Evidence for roots is often presented together with evidence for patterns, but here they are presented separately because the etymon theory also adopts the notion of the pattern. The review draws on evidence from the analysis of speech errors in both normal and aphasic patients, the analysis of first language data, well-formedness judgment tasks, paper-andpencil tasks, word naming tasks, and lexical decision tasks.

First, there is evidence from slips of the tongue that suggests that the root has a cognitive validity as a separate unit. Berg and Abd-El-Jawad (1996) found that Jordanian Arabic (JA) differs from German and English in single segment and metathesis slips of the tongue. JA errors display almost unconstrained metatheses between initial and final consonants within the word domain, thus targeting all root consonants. Errors in German and English, by contrast, tend to occur more often in initial position and respect the parallel syllable structure constraint. The latter constraint requires that a constituent exchanges places with a similar constituent. Thus, a coda should exchange positions with a coda. AbdEl-Jawad and Abu-Salim (1987) also report similar speech errors that give evidence for the separate status of roots.

Similar evidence is found in the rather artificial task of word games. Prunet, Béland, and Idrissi (2000) cite examples of word games where all consonants of the root undergo metathesis, but not affixal consonants.

The special separate status of the root is also apparent in the derivation of hypocoristics (Zawaydeh and Davis 1999 and Davis and Zawaydeh 2001). In this process, only the root consonants (in bold) are transferred from name to hypocoristic, as in muhammad (name) $\rightarrow$ hammūd (hypocoristic), from the root $h-m-d$ 'praise'.

Prunet, Béland, and Idrissi (2000), who studied the speech of an aphasic Arabic-French bilingual adult patient found similar results to the ones related to slips of the tongue reviewed above. They found that in the Arabic metathesis errors, the linear order of the consonants of the roots change but 'patterns and vowels remain intact' (p. 613). Besides, 'metatheses target the consonants of the root only. Affixal consonants (in

\footnotetext{
${ }^{6}$ For evidence for the root in Hebrew, consult Berent and Shimron (1997) for evidence from a well-formedness judgement task on the knowledge of the obligatory contour principle; Berman $(1981 ; 1997)$ for evidence from language acquisition studies; and Bentin and Feldman (1990), Feldman, and Bentin (1994), and Frost, Deutsch, Gilboa, Tannenbaum, and Marslen-Wilson (2000) for evidence from word recognition studies.
} 
prefixes, suffixes, and infixes) are never involved' (p. 614). Unlike in Arabic, the patient's metatheses in French are much less frequent and include not only reversal of adjacent and nonadjacent consonants, but also metathesis of a consonant and a vowel or syllables, as well as metathesis of vowels only. In a follow-up study, Idrissi, Prunet, and Béland (2002) found that metatheses affected even the underlying glides of weak roots; that is, glides that do not surface in the stimuli.

Further evidence for the root comes from a well-formedness judgment study. Frisch and Zawaydeh (2001) examined the tacit knowledge of the obligatory contour principle (OCP). The implication of the OCP for roots is a restriction against similar consonants in the first and second root consonants ${ }^{7}$. They found that native speakers showed a 'dispreference for roots containing repeated homorganic consonants' in novel verbs ( $\mathrm{p}$. 103). Frequency and similarity to existing roots were not significant factors. Gradiency/degree of violation, however, was important in the acceptance or rejection of a word. OCP-place (non)violation was of three degrees: (i) no OCP-place violation, (ii) one OCP-place violation, and (iii) identical root consonants ( $\mathrm{C} 1$ and $\mathrm{C} 2)$.

There is also evidence from acquisition of Arabic as a first language studies. Ravid (2003) reported on a few studies on the development of the root in Hebrew and Palestinian Arabic. The results of these studies indicated that as early as kindergarten native speakers of Hebrew and Palestinian Arabic showed awareness of the root in root relatedness tasks (telling the relation between words having the same root) and analogy tests (using the same root to create another word). This awareness increased with age, which was very likely due to linguistic development and literacy.

Lexical decision studies have shown that the priming effects of the root are distinct from phonology and semantics. Boudelaa and MarslenWilson (2005) examined the effect of the root as well as semantic and orthographic factors in different stages of the recognition process, at display time $32,48,64$, and $80 \mathrm{~ms}$, using two masked priming lexical decision experiments. The results of both experiments showed that morphological priming/the root was distinct from orthographic and semantic factors in the mentioned display conditions. In a similar study, Mahfoudhi (forthcoming) found a distinct priming effect of the root at a display time $50 \mathrm{~ms}$.

In visual lexical decision, a linguistic item (usually called a target) is

${ }^{7}$ For work on the constraints on the combination of the consonants of the root, see for instance Greenberg (1978) or McCarthy (1986). 
displayed on a computer screen for a short time (generally with a timeout of 2-3 ms) and the participant decides whether it is a word or a nonword by pressing a button. In the masked priming paradigm, the technique used in the present study, the prime (a linguistic item that appears before the target) is preceded by some pattern and/or other stimuli to mask it before the target item appears. Besides, the stimulus onset asynchrony (SOA) time is kept very short so that participants will not notice the prime. Masking is meant to eliminate any effect of episodic memory traces on repetition priming (cf. Evett and Humphreys 1981; Forster and Davis 1984). Masked priming has been found to be very sensitive to morphological priming, especially at short SOAs (Frost, Deutsch, and Forster 2000; Feldman and Bentin 1994), as well as to formal priming (orthography and phonology) (Forster and Taft 1994; Forster 1999). The assumption behind repetition priming in general is that the target word (the word to be identified on a computer screen) benefits from the preceding activation of a related prime, which could be either auditory or visual. The facilitating relationship between the prime and the target can be orthographic, phonological, semantic, or morphological.

Mimouni, Kehayia, and Jarema (1998) used an auditory priming paradigm (auditory signal as prime and a visual item as target) to examine morphological priming in Algerian Arabic-speaking normal and aphasic participants at SOA of $250 \mathrm{~ms}$. They found facilitation in word recognition when either regular or irregular plural nouns were primed by their singular counterparts with which they shared a root.

Boudelaa and Marslen-Wilson (2004b) examined whether allomorphs of roots (that undergo assimilation) prime sound roots in a lexical decision task with immediate cross-modal priming. They found that there was priming effect in the condition where there is only a morphological relation between the prime with the allomorph (a noun) and the target (a verb with a sound root), as well as with primes that shared meaning in addition to the abstract root. In both cases the priming was similar to that of the primes (nouns) and targets (verbs) that shared the same sound root. This is similar to the results reported for Hebrew, suggesting that processing seems to depend on the three root consonants even if one of its segments is different from that of the abstract underlying root.

\subsection{Evidence for patterns}

As for roots, there is evidence from speech errors for the pattern ${ }^{8}$. Abd-

8 The pattern has also received psycholinguistic support in Hebrew from studies of the speech errors of an aphasic (Barkai, cited in Prunet et al. 2000), 
El-Jawad and Abu-Salim (1987) report speech errors showing the pattern is extracted separately. Evidence from lexical decision tasks is inconclusive. Boudelaa and Marslen-Wilson (2005) found priming effect of this construct at display time 48 and $64 \mathrm{~ms}$ in deverbal nouns and only at SOA $48 \mathrm{~ms}$ in verbs. Moreover, Boudelaa and Marslen-Wilson (2004a) found evidence for the CV-skeleton with different vowels in primes in three lexical decision experiments using visual masked, auditory-visual, and auditory-auditory priming paradigms respectively. However, Mimouni, Kehayia and Jarema (1998) tested both normals and aphasic speakers of Algerian Arabic at SOA $250 \mathrm{~ms}$ using a cross-modal priming lexical decision task and found no effect of the pattern in nouns. Mahfoudhi (forthcoming) used a masked priming task and found no effect of the pattern in verbs at SOA $50 \mathrm{~ms}$.

\subsection{Evidence for etymons and phonetic matrices}

There is no previous research on the phonetic matrix and evidence for the etymon is both scarce and controversial. Evidence for the etymon comes from a lexical decision experiment on Arabic by Boudelaa and Marslen-Wilson (2001). They used two paradigms, cross-modal priming and masked priming, with the same stimuli. In addition to the control condition (i.e., a word totally unrelated to the target), three conditions were tested in the first experiment: (i) [+Etymon, + Sem] the prime was both semantically and morphologically related to the target; (ii) [+Etymon, -Sem] the prime and the target shared the etymon but were semantically unrelated (that is, the semantic relationship was diachronic but not synchronic); and (iii) [-Etymon, +Phon] the prime shared the same amount of phonological overlap (which is not linear as in concatenative languages) with the target, as in the case where they shared the same etymon, i.e., the first condition (i).

There was a significant effect of both the morphologically-related and the both semantically and morphologically-related primes. This means that there was no significant effect of the semantic transparency. This is similar to the results obtained in priming for roots in Arabic (Boudelaa and Marslen-Wilson 2005) and in Hebrew (Frost, Forster, and Deutsch 1997).

In the second experiment where they used masked priming, Boudelaa and Marslen-Wilson (2001) focused on the difference between 'the morphologically-related conditions [+Etymon, + Sem] and [+Etymon, - Sem]'

language acquisition studies (Berman 1997), and lexical decision studies with verbal patterns only (Deutsch, Frost, Forster 1998; Frost, Deutsch, Gilboa, Tannenbaum, and Marslen-Wilson 2000). 
and 'the phonological condition' (p. 78). The results showed significant differences between the morphological condition in comparison with both the phonological and the unrelated conditions. As in the first experiment, there was no significant difference between the semantically transparent and the semantically opaque morphological conditions.

Yet, Bentin and Frost (2001) cast doubt on these results. They designed a paper-and-pencil task to test whether native speakers of Arabic consciously knew the etymon. Twenty university students were asked to extract etymons from words after being told what an etymon was. The stimuli, which were taken from the data used in Boudelaa and MarslenWilson (2001), included 20 pairs of words, one from the prime and one from the target. The students 'correctly identified the etymon of only 27.2 words $(68 \%)$ out of the 40 words in the list' (p. 115). The authors considered this percentage too low to reflect knowledge of the etymon. Their claim was, however, not statistically tested. More importantly, they found that in 'only $50 \%$ of the pairs ( 10.1 out of 20 ) was the same etymon correctly identified for both the prime and the target.' (p. 115). This latter finding undermines the conclusion that the priming effects obtained in Boudelaa and Marslen-Wilson's study are morphological. Bentin and Frost also questioned the size of the priming effect obtained by Boudelaa and Marslen-Wilson, which they considered too large. They also questioned the fact that priming was almost the same in both the [+Etym, + Sem] and [+Etym, -Sem] conditions.

Other counterevidence against the cognitive relevance of the etymon comes from the speech of an aphasic patient (ZT). Idrissi and Kehayia (2004) examined the patient's metathesis errors on words that had potential etymons and found that only a few could be considered etymonrelated. In fact among the 64 metathesis errors made, only (17) $26.6 \%$ involved the etymon but $73.4 \%$ involved the metathesis of the extender (third consonant of the root in addition to the two of the etymon) and another consonant of the root/etymon (37), or the extender and both consonants of the etymon (11).

Some of Idrissi's and Kehayia's conclusions are not very convincing, though. It is true that the fact that the extender was metathesized is incompatible with the etymon theory, but the fact that $26.6 \%$ of the errors involved the etymon cannot be interpreted as evidence against the etymon. Given the number of errors and the number of consonant mutation possibilities of the root and the etymon, we expect the number of the mutations of root consonants to be three times as many as those involving the etymon, which was born out by the results, with a slight advantage for the etymon (73.4\% against $26.6 \%$ ). What really casts doubt on 
the relevance of the etymon as a morphological unit is the fact that the bipartite metathesis errors involving the extender and another root/ etymon consonant were significantly more frequent than those involving only the two etymon consonants. Given the inconclusiveness of these results, further research is necessary.

\section{The present study}

The present study examines the cognitive validity of the etymon and its more abstract form, the phonetic matrix, particularly, their relevance in the Arabic mental lexicon, using lexical decision with masked priming. The etymon in its segmental form is made up of two consonants that are shared in all the morphologically related words, either in the same or the reversed order. The phonetic matrix is the etymon in its most abstract form, where the two consonants share two place features only, which can also be ordered or not.

\subsection{Experiment 1: Etymons}

\subsubsection{Objectives}

This experiment aimed first to revisit the question of whether the etymon has a cognitive role in Arabic lexical representation and processing. As mentioned above, the only study on this issue to date was by Boudelaa and Marslen-Wilson (2001), whose results were met with much scepticism (e.g., Bentin and Frost 2001). In addition to attempting to replicate Boudelaa's and Marslen-Wilson's (2001) findings, the present study examined whether the order of the consonants of the etymon had an effect on the degree of priming, an issue that was not examined in Boudelaa and Marslen-Wilson (2001). If the etymon had a cognitive validity, we would expect a priming effect in the conditions where primes and targets share the same etymon (experimental variable) that is significantly different from the effects of phonology and orthography (control variable).

The experiment comprised three main conditions: (i) +Etymon (ordered or not) (Experimental condition), (ii) +Orthography/Phonology (control condition 1), and (iii) Unrelated (control condition 1), with 48 targets each. But to allow for an evaluation of the priming effect of ordered etymons in comparison to non-ordered etymons (in the first general condition), the target words were divided into two sets of three experimental conditions with 26 words with ordered etymons and 22 words with non-ordered etymons (see figure 1, below).

The first set included the following three conditions: (i) +Ordered Etymon, (ii) +Orthography/+Phonology, and (iii) Unrelated. In the first condition, primes and targets shared an ordered etymon. In the second condition (+Orthography/+Phonology), primes and targets shared two 
consonants (orthography/phonology), such that it mimicked the primetarget overlap in the morphological condition both in the number and the position of the shared consonants. In the third condition (Unrelated), primes and targets had roughly the same number of different letters (i.e., with no form or meaning similarity). A semantic condition was not included, because words with the same etymon were found, on the basis of a semantic relatedness judgment test administered to 20 native speakers, to have very little semantic relationship. In fact, they all had a mean score of less than 3 on a seven-point scale. The overall mean for all the prime-target pairs was 1.77 . The second set included, in addition to the +Orthography/+Phonology and Unrelated conditions, the +Non-ordered Etymon condition, in which primes and targets shared non-ordered etymons.

\subsubsection{Participants}

The participants were 36 Arabic-speaking students from Tunisia, where this and the next experiment were conducted. They were aged between 22 and 27 and all had at least 12 years of formal education in Arabic. They had all studied French as a second language for about 8 years. They had normal or corrected to normal vision. The participants in all experiments were volunteers. They were contacted on an individual basis in two university libraries (Faculté des Sciences Humaines et Sociales de Tunis and Institut Superieur des Langues de Tunis).

\subsubsection{Stimuli and design}

The targets were 48 triliteral Arabic verbs in the past tense third person singular form with a mean letter length of 4.25 and a mean syllable length of 3.52. Each of these words was paired with three primes, one from each of the experimental conditions described above (see figure 1 for a sample of the stimuli). The mean letter and syllable length of the primes that shared an ordered etymon with the targets was 3.52 and 3.01 respectively, and 3.36 and 2.82 respectively for the primes that shared a non-ordered etymon with the targets. In the orthographically/phonologically related condition, the primes were of a mean letter length of 3.59 and a mean syllable length of 3 . In the unrelated condition, the mean letter and syllable lengths were 3.42 and 3.08 respectively.

The number, position, order, and continuity of the overlapping letters in the orthographic/phonological control condition mimicked as much as possible those in the morphological condition. In the morphological condition, primes and targets shared an etymon that was either ordered or non-ordered. The primes in the three experimental conditions had the same word patterns and therefore roughly the same number of letters and 
the same syllable structure. The average amount of prime-target overlap was 2.40 letters and 2.42 phonemes in the morphological condition (2.39 letters and 2.43 phonemes in the ordered etymon condition and 2.41 letters and 2.41 phonemes in the unordered etymon condition). The primes in the orthographically/phonologically-related condition shared an average of 2.17 letters and 2.27 phonemes with the targets.

The verbs included mostly forms that have three consonants, two of which are believed to constitute the etymon, based on the work of Bohas and his students (Bohas 1997; 2000). Only a few weak verbs (verbs with a deleted underlying glide) that are believed to share an etymon with other verbs were included.

The 96 verbs selected in this study were of the following types: 19 verbs whose third consonant is a result of spreading/gemination, 22 verbs with an added consonant in initial (root-consonant) position, 22 verbs with an added consonant in second position, and 33 verbs with an added consonant in third position. The added consonant could be either a consonant or a glide (42 verbs had an added consonant and 35 had an added glide).

The stimuli had to have a familiarity score that ranged between 3 and 5 (on a seven-point scale). The overall mean scores within the different item types were as follows: 4.08 for the targets, 4.30 for the unrelated primes, 4.27 for the orthographically-related primes, and 4.13 for the items that share an etymon with the targets.

In addition to the 48 words and their corresponding primes in every condition, 144 fillers were selected. The fillers included 48 unrelated word-word fillers and 96 word-nonword pairs. Half of these pairs (48) were formally related whereas the other 48 pairs were unrelated and served as a control for the filler pairs. Each item file/list also contained 34 practice trials: 17 words and 17 non-words. The overlap in the related condition of the nonword-word pairs was morpho-phonological. The overlap in this condition, as in the experimental condition, included two ordered or non-ordered consonants of the root (a pseudo-etymon) and/or consonants from the affixes. Three lists were finally created; each containing a total of 226 pairs.

\subsubsection{Procedure and apparatus}

One third of the 36 participants were arbitrarily assigned to each of the three lists. They were tested individually in a quiet room. The participants were instructed to respond as quickly and as accurately as possible by pressing the Yes key for a word response and the No key for a nonword response. The dominant hand was used for word (Yes) responses 
and the non-dominant hand for the nonword (No) responses. The experiment lasted about 15 minutes. A training session with 34 practice items preceded the experiment.

Figure 1. Examples of Prime-Target Pairs Used in Experiment 1, with Arabic Script, Phonetic Transcription, and Gloss

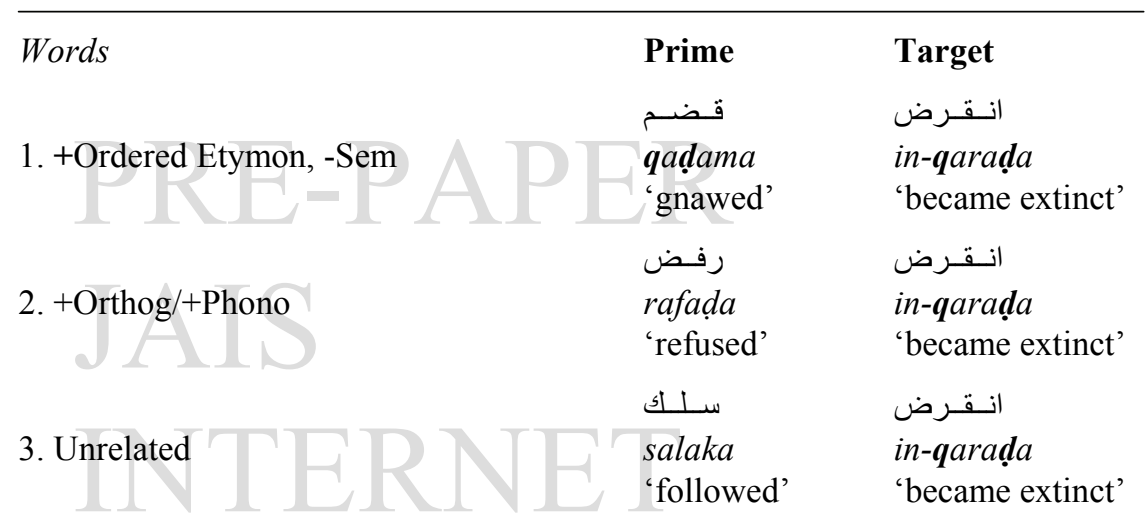

Set 2

1. +Non-ordered Etymon, -Sem

2. +Orthog/+Phono

3. Unrelated

Non-words

1. +Pseudo-etymon

2. +Orthog/+Phono

3. Unrelated

\begin{tabular}{|c|c|}
\hline مــوّه & اهــــمّم \\
\hline mawwaha & ihtamma \\
\hline 'feigned' & 'was interested' \\
\hline مــتـع & اهـــــمّ \\
\hline matta ${ }^{c} a$ & ihtamma \\
\hline 'made enjoy' & 'was interested' \\
\hline عـطسّل & اهــــمّم \\
\hline${ }^{c}$ atțala & ihtamma \\
\hline 'obstructed' & 'was interested' \\
\hline
\end{tabular}

قفز

qafaza 'jumped'<smiles>[CH]1[CH]C=C1</smiles>

'inšaqqa 'was split'

أطنـب

$$
\text { أعفز }
$$

[ $\left.{ }^{\mathrm{a}}{ }^{c} \boldsymbol{f} a \boldsymbol{z} a\right]$

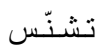

[tašannasa]

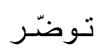

[tawaḍara]

This experiment and the following one were conducted on an HP 
portable computer (Pentium (R) $4 \mathrm{CPU} 2.66 \mathrm{GHz}$ ) running the display system DMDX ${ }^{9}$. Each trial consisted of three events. The first event was a mask of 28 vertical lines that was displayed for $500 \mathrm{~ms}$. The second event that immediately followed was a prime word that appeared for $50.25 \mathrm{~ms}$ (three ticks of $16.75 \mathrm{~ms}$ each). The last event that immediately followed the prime was a target word, which remained on the screen for $2000 \mathrm{~ms}$ or until a response was provided by pressing a button on a USB joystick. The mask was presented in 30-point Traditional Arabic font size, the prime in 24-point font size, and the target in 34-point font size.

\subsubsection{Results}

Means for both correct response times and error frequencies were obtained for both participants and items. Any correct response that was two standard deviations above or below the mean of each participant was eliminated without being replaced. This eliminated $3.46 \%$ of the data. The overall error rate was 12.7 . The effect of priming in the related condition was evaluated against the baseline orthographic/phonological condition. The means, standard deviations, and error rates for all experimental conditions are presented in Table 1.

Because the etymon is theoretically conceived of as an overlap in two 'radical' consonants that may or may not be ordered, I ran a first set of analysis of variance tests (ANOVAs) in which the morphologicallyrelated condition included a balanced number of ordered and nonordered etymons. The conditions were therefore the following: +Etymon (ordered or non-ordered), +Orthography/Phonology, and Unrelated. The prime condition was significant by subjects, $\mathrm{F}_{1}(2,66)=8.66, p<.001$. Planned comparisons revealed a significant difference between the +Etymon condition and the unrelated condition, $\mathrm{F}_{1}(1,33)=18.98, p$ $<.001$ as well as between the +Etymon condition and the form condition (+Orthography/Phonology), $\mathrm{F}_{1}(1,33)=7.74, p<.01$. The form condition did not differ from the unrelated condition, $\mathrm{F}_{1}(1,33)=2.45, p>.05$. Error analysis did not show any significant differences between the conditions.

To see whether the order of the etymon consonants had an effect on priming, I further ran two sets of ANOVAs. The first included the +Ordered Etymon, +Orthography/Phonology, and Unrelated conditions. Prime condition was significant, $\mathrm{F}_{1}(2,66)=4.56, p<.01$. Planned comparisons, using the deviation contrast, showed that only the morphological condition had a significant effect, $\mathrm{F}_{1}(1,33)=6.92, p<.01$.

9 The DMDX software was developed by J. C. Forster at the University of Arizona. 
In the other set of ANOVAs the +Non-ordered Etymon condition, the form condition, and the control condition were compared. The prime condition was not significant either by subjects $\left(\mathrm{F}_{1}(2,64)=.55, p>.05\right)$ or by items $\left(\mathrm{F}_{2}(2,57)=.07, p>.05\right)$.

Table 1. Lexical Decision Reaction Times (RT), Standard Deviations (SD), and Percentage Error Rates (\% error) in Experiment 1

\begin{tabular}{llll}
\hline \multicolumn{1}{c}{ Condition } & $\mathrm{RT}(\mathrm{ms})$ & $\mathrm{SD}$ & \% error \\
\hline 1. +Etymon+/-ordered & 800 & 113 & 10.9 \\
2. +Orthog/+Phono & 816 & 118 & 12.4 \\
3. Unrelated & 828 & 120 & 14.9 \\
1a. +Ordered etymon & 774 & 115 & 12.4 \\
2a. +Orthog/+Phono & 781 & 118 & 14.2 \\
3a. Unrelated & 800 & 123 & 12.4 \\
1b. +Non-ordered etym & 832 & 134 & 10.7 \\
2b. +Orthog/+Phono & 842 & 132 & 9.1 \\
3b. Unrelated & 840 & 130 & 14.3 \\
\hline
\end{tabular}

\subsubsection{Discussion}

The results partly replicate what has previously been reported about the priming effect of etymons in Arabic by Boudelaa and Marslen-Wilson (2001). Despite the fact that the present experiment included both ordered and non-ordered etymons, I found a significant effect in the morphological (+Etymon) condition, which included prime target pairs that shared either ordered or non-ordered etymons. Boudelaa and MarslenWilson, who used mostly ordered etymons, suggested on the basis of their findings that the etymon is used in lexical processing.

What is new in the present experiment is the fact that priming occurs only when the primes and targets share an ordered etymon. This result casts some doubt on this construct. Yet, we cannot conclude that the effect is due to orthographic/phonological overlap, because the effect of the etymon consonants is largely significantly different from the effect of orthography/phonology (a difference of $16 \mathrm{~ms}$ ). I might, however, suggest that the construct used in the activation of lexical representations is not as abstract as the theoretical construct proposed in morphological theory. The cognitive construct is very likely a formal (orthographic) ordered unit that might be related to the root.

\subsection{Experiment 2: Phonetic matrices}

\subsubsection{Objectives}

The phonetic matrix has not been examined in previous research. Boudelaa and Marslen-Wilson (2001) mentioned the notion of the matrix as the underlying unifying unit of etymons, but actually used mostly 
etymons that shared two phonemes. The purpose of the present experiment was to investigate whether a prime would facilitate the recognition of a target word with which it shared the phonetic features assumed to be unifying etymons (see section 2 for a detailed discussion of the notions of phonetic matrix and etymon). Since I did not find any priming with non-ordered etymons, I did not expect to find priming with the very abstract notion/construct of phonetic matrix.

Three conditions were studied. In the morphological condition [+Phonetic Matrix, -Semantics] (Experimental condition), primes and targets shared a phonetic matrix, namely two place features that related etymons share (see figure 2 for examples of the different prime-target pairs in the different conditions). Primes in the phonological condition [+Phonology, -Semantics] (control condition 1), as in the related condition, were related to the target by sharing roughly the same number and order of features/phonemes. The only difference was that in the phonological condition the primes shared only one feature of the matrix features with the targets. In cases where a morphologically related prime and a target shared an additional letter in addition to the shared matrix, it was repeated in the phonological condition. In the unrelated condition (control condition 2), primes and targets shared one or no phonetic feature. The shared feature had to be other than the two place features making the matrix in the morphological condition or any other matrix. There were a few cases where an extra overlap was found in the affixes of the unrelated condition. These were theoretically irrelevant and could not be avoided when the patterns of the primes had to be as similar as possible.

In all conditions, the short vowels were not considered in the overlap. First, vowels are not part of the root/etymon. Second, vowels do not show in the orthographic transcription. To assure an optimal control over the variation, there were two cases in which all primes including the unrelated primes shared the word pattern with the targets (the focus was on the variation of the matrix features). The three experimental primes had in most cases the same pattern and the same number of letters/phonemes.

If the phonetic matrix had an effect in lexical processing, primes in the matrix-related condition should prime their targets significantly more than the phonological controls. As mentioned earlier, I predicted no priming effect.

\subsubsection{Participants}

The participants were another 36 Arabic-speaking students from the same population as in the previous experiment. None had participated in 
Experiment 1. The recruitment procedure was the same as in the first experiment.

\subsubsection{Stimuli and design}

The choice of the words was based on the work of Bohas and his students (Bohas 1997; 2000). The words belonged to one of the following seven matrix-based groups:

(i) $\{[$ labial], [coronal] $\}$

(ii) $\{[+$ consonantal, labial $]$ [+consonantal, -voiced, + continuous $]\}$

(iii) $\{[$ labial, -sonorant $]$, [pharyngeal $]\}$

(iv) $\{$ [coronal], [pharyngeal, -dorsal, -voiced] $\}$

(v) $\{$ [coronal $]$, [dorsal $]\}$

(vi) $\{[$ labial, -sonorant], [dorsal]\}

(For a feature-based description of Arabic consonants, the reader is referred to appendix A and to appendix B for the consonants associated with each of the above mentioned matrices.)

A matrix also includes words that share the same etymon/two phonemes, but these were paired with words with which they shared only the specified phonetic features, not whole phonemes.

The stimuli included triliteral Arabic verbs. The targets were 36 words/verbs whose mean letter length was 4.17 and mean syllable length was 3.53. Each of the target words was paired with three primes, one from each of the experimental conditions: (i) the [+Matrix, -Semantics] condition, (ii) the [+Phonology, -Semantics] condition, and (iii) the Unrelated condition. The primes that shared a phonetic matrix with the targets (morphological condition) were, on average, 3.31 letters long and had an average of 2.97 syllables. The phonological primes also had an average of 3.31 letters and 2.97 syllables. The mean letter and syllable length of the unrelated primes were 3.28 and 2.86, respectively.

In most cases, primes in the three conditions had the same word patterns, which were, in every case, different from those of the targets. The overlap between primes and targets was in terms of phonetic features as well as whole phonemes. Only the segmental overlap is reported here. The primes in the matrix-related (morphological) condition shared with the targets an average of 0.92 letters and 0.97 phonemes. In the phonological condition, primes and targets shared an average of 0.89 letters and 0.92 phonemes.

As in Experiment 1, the items were selected on the basis of a familiarity judgement made by 30 native speakers. The criterion of selection was a mean familiarity score that ranged between 3.5 and 5.5. The overall 
mean scores were distributed as follows: 4.02 for the targets, 4.05 for the unrelated items, 4.30 for the phonologically related items and 3.98 for the primes that shared a phonetic matrix with the targets. Because the non-words were not examined, a strict criterion of selection of words was not observed. The word-nonword pairs that served as controls for the matrix related words did not share any phonemes, very much like the unrelated word-nonword pairs. No attention was paid to the features of the phonetic matrices studied, because these were not included in the analysis.

Figure 2. Examples of Prime-target Pairs Used in Experiment 2, with Arabic Script, Phonetic Transcription, and Gloss

\begin{tabular}{|c|c|c|}
\hline & Prime & Target \\
\hline . +Matrix, -Semantics & $\begin{aligned} \text { lafaha } \\
\text { ‘(a hot wind) blew' }\end{aligned}$ & $\begin{array}{l}\text { naffasa } \\
\text { 'relieved' }\end{array}$ \\
\hline + +Phonology & $\begin{array}{l}\text { farada } \\
\text { 'imposed' }\end{array}$ & $\begin{array}{l}\text { naffasa } \\
\text { 'relieved' }\end{array}$ \\
\hline Unrelated & $\begin{array}{l}\text { عـلــ } \\
\text { 'aliqa } \\
\text { 'stuck' }\end{array}$ & $\begin{array}{l}\text { naffasa } \\
\text { 'relieved' }\end{array}$ \\
\hline
\end{tabular}

Non-words

1. No phonology

\begin{tabular}{|c|c|}
\hline كظم & تخخاثل \\
\hline $\begin{array}{l}\text { kazama } \\
\text { 'suppressed' }\end{array}$ & [tahāâtala] \\
\hline تـلاء م & اقتظر \\
\hline $\begin{array}{l}\text { talä'ama } \\
\text { 'fit' }\end{array}$ & [iqtazara] \\
\hline لَحَن & تكارف \\
\hline $\begin{array}{l}\text { lahhanana } \\
\text { 'composed' }\end{array}$ & [takārafa] \\
\hline
\end{tabular}

Three lists were created. Each list contained, in addition to the 36 experimental pairs, 111 filler pairs, 36 of which were word-word pairs, and 72 word-nonword pairs. A total of 34 practice pairs were also included. Thus, each list contained a total of 178 pairs.

\subsubsection{Procedure and apparatus}

This was the same as in the previous experiment. 


\subsubsection{Results}

The RT and error data were cleaned as in the previous experiment, which resulted in the elimination without replacement of a small part of the data (4.2\%). The effect of priming in the related conditions was compared to the phonological condition. The means, standard deviations, and error rates for all experimental conditions are presented in table 2 .

The prime condition variable was not significant either in the response time analysis $\left(\mathrm{F}_{1}(2,66)=3.09, p>.05\right.$ and $\left.\mathrm{F}_{2}(2,99)=.21, p>.05\right)$ or in the error analysis $\left(\mathrm{F}_{1}(2,66)=1.86, p>.05\right.$ and $\left.\mathrm{F}_{2}(2,99)=.88, p>.05\right)$.

Table 2. Lexical Decision Reaction Times (RT), Standard Deviations (SD), and Percentage Error Rates (\% error) in Experiment 2

\begin{tabular}{llll}
\hline \multicolumn{1}{c}{ Condition } & RT $(\mathrm{ms})$ & SD & \% error \\
\hline 1. +Matrix & 791 & 131 & 13.1 \\
2. +Phono & 776 & 128 & 9.6 \\
3b. Unrelated & 780 & 130 & 13.7 \\
\hline
\end{tabular}

\subsubsection{Discussion}

The results clearly show that the phonetic matrix has no priming effect. As discussed above (section 2), the phonetic matrix is the very abstract and general construct that underlies etymons that share the same matrix of phonetic features. The lack of priming by the phonetic matrix was expected, especially since no priming was found with the non-ordered etymon, which is a much less abstract manifestation of the phonetic matrix.

It should be noted, nonetheless, that in testing so abstract a construct and where the relation between primes and targets is not visually observable, it would have been better to use as well a cross-modal audio-visual lexical decision task.

\section{General discussion}

The objective of this study was to see what place the etymon and matrix have in the Arabic mental lexicon. The results of this study are not straightforward, very much like what has been found about the etymon up to now. This study has replicated the findings of Boudelaa and MarslenWilson (2001) about the priming effect of the etymon in its ordered segmental sense. If we consider these results sufficient, we might accept that the etymon has a place as a separate entity in the Arabic mental lexicon or even as a morpheme, although, as argued above, Bohas does not claim it to be such. This conclusion would support an etymon-based theory of the Arabic lexicon. Yet, the new finding in this study is that priming does not occur when the shared two consonants of the etymon are non-ordered 
and when the two consonants of this unit share only two place features with other derivational relatives. Localist theories (such as the dual access hypothesis, discussed above) adopt a lexical entry-opening access in word recognition and assume an all-or-none priming effect of morphemes. According to these theories, if the etymon has a special separate status or is a morpheme, it should facilitate access regardless of whether it is ordered or non-ordered. Still, it could be argued from a localist standpoint that the absence of priming with non-ordered etymons is due to a constraint on abstractness in lexical processing. It could be argued that lexical processing is not abstract enough to pick on the non-ordered consonants of etymons or the phonetic matrices in word recognition. The experimental results of this study together with the previous ones do not provide strong evidence for the etymon.

The notion of the etymon (i.e., both the etymon and matrix) is also vulnerable from a theoretical point of view. For one thing, we are not sure where the etymon comes from, if it is not a morpheme as Bohas (2000) suggests. Another theoretical problem with the etymon is that there are no clear criteria/rules to identify this unit in a word, especially as its consonants can be non-ordered and even share only phonetic features (rather than segments) with the other members of the word family and the etymon- related words might share little meaning.

In summary, the results of this study have shown that the psycholinguistic evidence for the notion of the etymon is as complex as the construct itself. While there is psycholinguistic evidence for the etymon in its ordered version that corroborates a previous study by Boudelaa and Marslen-Wilson (2001), the non-ordered version of the etymon and its more abstract form (the phonetic matrix) could not be supported by psycholinguistic data. Furthermore, the theoretical literature for the etymon, such as criteria for identifying it, as well as how it is used in a derivational formalism to be developed into a 'radical', is still far from being well-developed. The root remains a stronger notion than the etymon to account for the organization of the Arabic mental lexicon. 


\section{REFERENCES}

Abdel-El-Jawad, H., and I. Abu-Salim. 1987. 'Slips of the Tongue in Arabic and Their Theoretical Implications'. Language Sciences 9: 145-71.

Bat-El, O. 1994. 'Stem Modification and Cluster Transfer in Modern Hebrew'. Natural Language and Linguistic Theory 12: 571-96.

Benmamoun, E. 1999. 'Arabic Morphology: The Central Role of the Imperfective'. Lingua 108: 175-201.

Bentin, S., and L. B. Feldman. 1990. 'The Contribution of Morphological and Semantic Relatedness to Repetition Priming at Short and Long Lags: Evidence from Hebrew'. Quarterly Journal of Experimental Psychology 42a: 693-711.

Bentin, S., and R. Frost. 2001. 'Linguistic Theory and Psychological Reality: A Reply to Boudelaa and Marslen-Wilson'. Cognition 81: 113-18.

Berent, I., and J. Shimron. 1997. 'The Representation of Hebrew Words: Evidence from the Obligatory Contour Principle'. Cognition 64: 39-72.

Berg, T., and H. Abd-El-Jawad. 1996. 'The Unfolding of the Suprasegmental Representations: A Crosslinguistic Perspective'. Journal of Linguistics 32: 291-324.

Berman, R. A. 1981. 'Language Development and Language Knowledge: Evidence from the Acquisition of Hebrew Morphology'. Journal of Child Language 8: 609-26.

1997. 'The Acquisition of Hebrew'. In D. I. Slobin, ed., The CrossLinguistic Study of Language Acquisition, 1: 255-371. Hillsdale, NJ: Lawrence Erlbaum Associates, Inc.

Bohas, G. 1997. Matrices, étymons, racines: Éléments d'une théorie lexicologique du vocabulaire arabe, Orbis, Supplementa 8. Louvain: Peeters. . 2000. Matrices et étymons: Développements de la théorie. Lausanne: Éditions du Zèbre.

Bohas, G., and J-P. Guillaume. 1984. Étude des théories des grammariens arabes: Morphologie et phonologie. Damas: Institut Français de Damas.

Bohas, G., and A. Saguer. 2006. 'La cerise sur le gâteau: Explication de l' homonymie'. Seminaire de Toulouse IRPALL. Unpublished manuscript.

Boudelaa, S., and W. D. Marslen-Wilson. 2001. 'Morphological Units in the Arabic Mental Lexicon'. Cognition 81: 65-92.

2. 2004a, 'Abstract Morphemes and Lexical Representation: The CVSkeleton in Arabic'. Cognition 92: 271-303.

- 2004b. 'Allomorphic Variation in Arabic: Implications for Lexical Processing and Representation'. Brain and Language, 90: 106-16.

- 2005. 'Discontinuous Morphology in Time: Incremental Masked Priming in Arabic'. Language and Cognitive Processes 20(1-2): 207-60.

Broselow, E., and J. McCarthy. 1983. 'A Theory of Internal Reduplication.' The Linguistic Review 3: 25-88. 
Butterworth, B. 1983. 'Lexical Representation'. In B. Butterworth, ed., Language Production. 2: 257-94. London: Academic Press.

Cantineau, J. 1950a. 'Racines et schèmes'. In W. Marcais, ed., Mélanges, 11924. Paris: Maisonneuve et Cie.

1950b. 'La notion de schème et son altération dans diverses langues sémitiques'. Semitica 3: 73-83.

Caramazza, A., A. Laudanna, and C. Romani. 1988. 'Lexical Access and Inflectional Morphology'. Cognition 28: 297-332.

Davis, S., and B. Zawaydeh. 2001. 'Arabic Hypocoristics and the Status of the Consonantal Root'. Linguistic Inquiry 32: 512-20 (in remarks and replies).

Deutsch, A., R. Frost, and K. I. Forster. 1998. 'Verbs and Nouns are Organized and Accessed Differently in the Mental Lexicon: Evidence from Hebrew'. Journal of Experimental Psychology: Learning, Memory, and Cognition 24(5): 1238-55.

Evett, L. J., and G. W. Humphreys. 1981. 'The Use of Abstract Graphemic Information in Lexical Access'. Quarterly Journal of Experimental Psychology 33: $325-50$.

Feldman, L. B., and S. Bentin. 1994. 'Morphological Analysis of Disrupted Morphemes: Evidence from Hebrew'. The Quarterly Journal of Experimental Psychology 47A(2): 407-35.

Forster, K. I. 1999. 'The Microgenesis of Priming Effects in Lexical Access'. Brain and Language 68: 5-15.

Forster, K. I., and C. Davis. 1984. 'Repetition Priming and Frequency Attenuation in Lexical Access'. Journal of Experimental Psychology: Learning, Memory, and Cognition 10(4): 680-98.

Forster, K. I., and M. Taft. 1994. 'Bodies, Antibodies, and NeighborhoodDensity Effects in Masked Form Priming'. Journal of Experimental Psychology: Learning, Memory, and Cognition 20: 844-63.

Frisch, S. A., and B. A. Zawaydeh. 2001. 'The Psychological Reality of OCPPlace in Arabic'. Language 77(1): 91-106.

Frost, R., A. Deutsch, and K. I. Forster. 2000. 'Decomposing Morphologically Complex Words in Nonlinear Morphology'. Journal of Experimental Psychology: Learning, Memory, and Cognition 26(3): 751-65.

Frost, R., A. Deutsch, O. Gilboa, M. Tannenbaum, and W. Marslen-Wilson. 2000. 'Morphological Priming: Dissociation of Phonological, Semantic, and Phonological Factors'. Memory and Cognition 28(8): 1277-88.

Frost, R., K Forster, and A. Deutsch. 1997. 'What Can We Learn from the Morphology of Hebrew? A Masked-Priming Investigation of Morphological Representations'. Journal of Experimental Psychology: Learning, Memory, and Cognition 23: 829-56.

Goldsmith, J. 1976. 'An Overview of Autosegmental Phonology'. Linguistic Analysis 2(1): 23-68.

1978. 'The Patterning of Root Morphemes in Semitic'. In S. Al-Ani. ed., Readings in Arabic Linguistics, 431-53. Bloomington, IN: Indiana Uni- 
versity Linguistics Club.

Hoberman, R. D., andM. Aronoff. 2003. 'The Verbal Morphology of Maltese'. In J. Shimron, ed., Language Processing and Language Acquisition in Languages of Semitic, Root-Based Morphology, 61-78. Amsterdam: John Benjamins.

Idrissi, A., and E. Kehayia. 2004. 'Morphological Units in the Arabic Mental Lexicon: Evidence from an Individual with Deep Dyslexia'. Brain and Language, 90: 183-97.

Idrissi, A., J-F. Prunet, and R. Béland. 2002. 'Metathesis Errors in Aphasic Speech: Implications for the Status of Abstract Roots in Arabic'. Brain and Language (in Abstracts) 83(1): 90-92.

Mahfoudhi, A. Forthcoming 2007. 'Roots and Patterns in Arabic Lexical Processing'. In Elabbas Benmamoun, ed., Perspectives on Arabic Linguistics 19. Amsterdam: Benjamins.

Marantz, A. 1982. 'Re Reduplication'. Linguistic Inquiry 13: 483-545.

McCarthy, J. J. 1979/1982), Formal Problems in Semitic Phonology and Morphology. PhD. Dissertation, Massachusetts Institute of Technology, Cambridge, MA (reproduced by the Indiana University Linguistics Club, Bloomington, Indiana).

- 1981. 'A Prosodic Theory of Non-Concatenative Morphology'. Linguistic Inquiry 12: 373-418.

. 1986. 'OCP Effects: Gemination and Antigemination'. Linguistic Inquiry 17(2): 207-63.

McCarthy, J., and A. Prince. 1990. 'Prosodic Morphology and Templatic Morphology'. In M. Eid and J. McCarthy, eds., Perspectives on Arabic Linguistics, 2: 1-54, Amsterdam: John Benjamins.

1999. 'Prosodic Morphology'. In J. A. Goldsmith, ed., Phonological Theory, 238-88. Malden, MA: Blackwell Publishers.

Mimouni, Z., E. Kehayia, and G. Jarema. 1998. 'The Mental Representation of Singular and Plural Nouns in Algerian Arabic as Revealed through Auditory Priming in Agrammatic Aphasic Patients'. Brain and Language 61: 63-87.

Prunet, J-F., R. Béland, and A. Idrissi. 2000. 'The Mental Representation of Semitic Words'. Linguistic Inquiry 31(4): 609-48.

Rajhi, A. 1974. Al-Tațbìq al-șarfì (Practical morphology). Beirut, Lebanon: Dār al-Nahḍa al- ${ }^{\mathrm{c}}$ Arabiyya.

Ratcliffe, R. R. 1997. 'Prosodic Templates in a Word-Based Morphological Analysis of Arabic'. In M. Eid and R. R. Ratcliffe, eds., Perspectives on Arabic Linguistics, 10: 147-71. Amsterdam: John Benjamins.

Ravid, D. 2003. 'A Developmental Perspective on Root Perception in Hebrew and Palestinian Arabic'. In J. Shimron, ed., Language Processing and Language Acquisition in Languages of Semitic, Root-Based Morphology, 293319. Amsterdam: John Benjamins.

Taft, M. 1981. 'Prefix Stripping Revisited'. Journal of Verbal Learning and Verbal Behavior 20: 289-97. 
Ussishkin, A. P. 1999. 'The Inadequacy of the Consonantal Root: Modern Hebrew Denominal Verbs and Output-Output Correspondence'. Phonology 16: 401-42.

Watson, J. 2002. The Phonology and Morphology of Arabic. Oxford: Oxford University Press.

Zawaydeh, B., and S. Davis. 1999. 'Arabic Hypocoristics and Their Implications'. Unpublished conference paper presented at the Linguistic Society of America Meeting, Los Angeles, CA. 


\section{APPENDICES}

\section{Appendix A}

Features of Arabic Consonants (Based on Bohas 2000, 18)

\begin{tabular}{|c|c|c|c|c|c|c|c|c|c|c|c|c|c|}
\hline & $\mathrm{z}$ & $\underline{s}$ & 1 & $\mathrm{n}$ & $\mathrm{r}$ & $\mathrm{k}$ & $\mathrm{q}$ & h & $\dot{\mathrm{g}}$ & h & c & o & $\mathrm{h}$ \\
\hline ) & ظ & ص ص ص & J & ن & ر & 5 & ق & $\dot{\tau}$ & $\dot{\varepsilon}$ & $\tau$ & $\varepsilon$ & $\&$ & 。 \\
\hline$[+/$-cons $]$ & + & + & + & + & + & + & + & + & + & + & + & & \\
\hline [+/-sonr] & - & - & + & + & + & - & - & + & + & + & + & + & + \\
\hline [+/-approx] & - & - & + & - & + & - & - & + & + & + & + & - & + \\
\hline [+/-voiced] & + & - & + & + & + & - & - & - & + & - & + & - & - \\
\hline$[+/$-contin $]$ & + & + & - & - & + & - & - & + & + & + & + & - & + \\
\hline [labial] & & & & & & & & & & & & & \\
\hline [coronal] & + & + & + & + & + & 11 & & & & & & & \\
\hline [dorsal] & + & + & 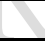 & T & 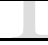 & + & + & + & + & & & & \\
\hline [pharyngeal] & + & + & & & & & + & + & + & + & + & + & + \\
\hline
\end{tabular}

\begin{tabular}{|c|c|c|c|c|c|c|c|c|c|c|c|c|c|}
\hline & $\mathrm{m}$ & $\mathrm{b}$ & $\mathrm{f}$ & $\underline{\mathrm{t}}$ & $\underline{d}$ & $\mathrm{t}$ & $\mathrm{d}$ & $\mathrm{s}$ & $\mathrm{z}$ & š & ğ & $t \underline{t}$ & ḍ \\
\hline & 5 & ب ب & ف & ث & j & ت ت & د & س & j & ش - م ش & ج & b & 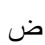 \\
\hline$[+/$-cons $]$ & + & + & + & + & + & + & + & + & + & + & + & + & + \\
\hline [+/-sonr $]$ & + & - & - & - & - & - & - & - & - & - & - & - & - \\
\hline [+/-approx] & - & - & - & $\begin{array}{lll}- \\
-\end{array}$ & - & - & - & - & $\begin{array}{ll}- \\
-\end{array}$ & - & - & - & - \\
\hline [+/-voiced $]$ & + & + & - & - & + & - & + & - & + & - & + & - & + \\
\hline [+/-contin] & - & - & + & + & + & - & - & + & + & + & + & - & - \\
\hline [labial] & + & + & + & & & & & & & & & & \\
\hline [coronal] & & & & + & + & + & + & + & + & + & + & + & + \\
\hline [dorsal] & & & & & & & & & & & & + & + \\
\hline [pharyngeal] & & & & & & & & & & & & + & + \\
\hline
\end{tabular}




\begin{abstract}
Appendix B
Phonetic Matrices in Arabic and the Phonemes Belonging to Them (Bohas 1997 and 2000)

The following is a list of the different phonetic matrices proposed for Arabic and the (etymon) phonemes that correspond to them. For a word to be part of a phonetic matrix, it has to have two phonemes with each having one place feature of the two main features of the matrix. For instance, for an Arabic word to be within the phonetic matrix $\{[$ labial], [coronal]\} it needs to have one phoneme that has the feature [labial] and another phoneme with the feature [coronal]. In other words, it has to have either an $/ \mathrm{m} /, \mathrm{a} / \mathrm{b} /$, or an $/ \mathrm{f} /$ and one of the following

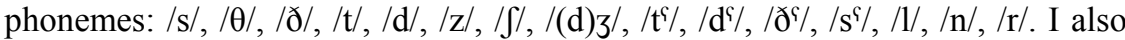
included the very general meaning (signification commune primordiale) corresponding to each phonetic matrix.
\end{abstract}

a. $\{[$ labial], [coronal]\}: 'porter un coup ou des coups (sans spécifier l'objet)' (Bohas 2000, 69),

[labial]: $/ \mathrm{m} /, / \mathrm{b} /, / \mathrm{f} /$

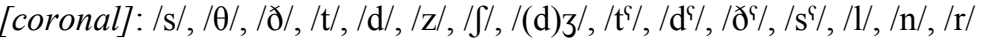

b. $\{[+$ consonantal, labial], [+consonantal, -voiced, +continuous $]\}$ : 'mouvement de l'air: vent, soufflé; expulsion de l'air chez l'homme ou l'animal' (Bohas 2000, 82),

[labial]: /m/, /b/, /f/

[-voiced, + continuous]: /f/, / / /, /s/, /s/,/s'/, /h/, /x/, /h/

c. $\{[$ labial, -sonorant], [pharyngeal]\}: 'lier’ (Bohas 2000, 85)

[labial, -sonorant]:/b/, /f/

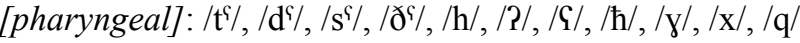

d. $\{[$ coronal], [pharyngeal, -dorsal, -voiced]\}: 'produire un bruit sourd, rauque' (Bohas 2000, 89),

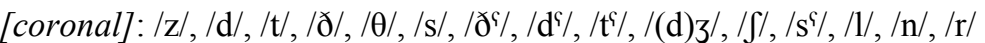
[pharyngeal, -dorsal, -voiced]: /h/,/2/,/h/

e. $\{[$ coronal], [dorsal]\}: 'couper' (Bohas 2000, 117),

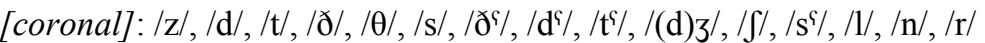

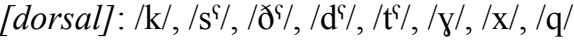

f. $\{[$ labial, -sonorant], [dorsal] $\}$ : meanings related to 'la forme $\frown$ disposée de diverses manières, ce que Nicolaï a appelé la courbure' (Bohas 2000, 90-91),

[labial, -sonorant]: /f/, /b/

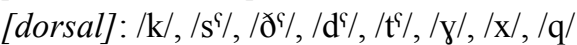

